DOI 10.37882/2500-3682.2020.09.16

\title{
ГЛОБАЛИЗАЦИЯ И ДИВЕРСИФИКАЦИЯ СОВРЕМЕННОГО ПРОСТРАНСТВА КУЛЬТУРЫ
}

\section{GLOBALIZATION AND DIVERSIFICATION IN THE MODERN CULTURAL SPACE \\ L. Smetankina S. Mikhalev}

Summary: The problems of globalization take their place in many scientific studies. However, despite the fact that nowadays the problems of the cultural development of both separate countries and the whole society are quite important, cultural globalization as a process of integrating heterogeneous and multi-level cultures into the global cultural space has not yet been studied yet. The authors of the article draw attention to the peculiarities of cultural globalization process. They also touch upon such a phenomenon of cultural identity as diversification, which is a vector of development and interaction of cultures in the global space.

Keywords: culture, cultural space, globalization, diversification, national identity.
Сметанкина Людмила Васильевна

Д.ф.н., nрофрессор, ФГКВОУ ВО «Военная академия связи имени Маршала Советского Союза С.М. Буденного» МО РФ

Ismetankina.umo@mail.ru

Михалёв Сергей Александрович

К.ф.н., дочент, ФГКВОУ ВО «Военная академия связи имени Маршала Советского Союза С.М. Буденного» МО РФ

sermichalev@yandex.ru

Аннотация: Проблемы глобализации находят свое место во многих научных исследованиях. Однако, несмотря на то, что сегодня вопросы культурного развития как отдельных стран, так и мирового сообщества в целом обретают особую значимость, культурная глобализация как процесс интеграции разнородных и разноуровневых культур в глобальное пространство культуры пока еще недостаточно исследована. В данной статье авторы обращают внимание на особенности глобализационных процессов, происходящие в культуре, по ходу затрагивая такое явление культурной идентичности, как диверсификация, в свою очередь, являющаяся вектором развития и взаимодействия культур в глобальном пространстве.

Ключевые слова: культура, культурное пространство, глобализация, диверсификация, национальная идентичность.

ний, пожалуй, нет иной сферы общественной жизни, помимо культуры, которая обсуждалась бы так активно и вызывала бы так много дискуссий и разногласий. Причин тому много, но главной причиной того, что культурной глобализации отводится так много места в монографиях, статьях, обычных размышлениях на страницах периодической печати и на Интернет-форумах, является, с точки зрения А.Н. Чумакова, «универсальный характер культуры, являющейся главной характеристикой как самого человека, так и всех общественных структур» $[10$, с. 8]. Общественное бытие, по мнению данного исследователя, «немыслимо вне культурного контекста» [10, с. 8], т.к. культура, «базируясь на дозволяемых и воспроизводимых обществом (этносом, нацией, государством) нормах и ценностях» [5, с. 79], охватывает и, более того, буквально пронизывает все сферы духовной и материальной жизни общества» $[10$, с. 8]. А поскольку «культура «как целостная система, внутри которой пребывает человек и с которой он соучаствует» [5, с. 79], «образует единое целое с наиболее важными социальными событиями и процессами» [1, с. 48], то процессы глобализации, прежде всего, затрагивают культуру и непосредственным образом с ней связаны.

Культурная глобализация - явление не новое. Истоки универсализации культуры «можно обнаружить и на заре Новой истории, и гораздо раньше во времена

В осмыслении современных глобальных измене- 
распространения мировых религий и элитарной культуры Римской империи. Однако, именно сегодня культурная глобализация переживает бум. Интенсивное развитие коммуникаций, средств связи и информационных технологий во второй половине XX века привело к расширению объема, увеличению разнообразия и ускорению глобальных культурных потоков, повышению интенсивности и скорости культурного обмена» [3, с. 19].

Культурному пространству современности присущи две комплементарные направленности - интеграция, сформировавшая массовую культуру, которая претендует на роль глобальной культуры, и диверсификация, умножающая полиморфию устоявшихся культурных сообществ.

Так называемой массовой культуре свойственно структурное неравенство, о чем говорят все теоретики культурной глобализации. По мысли Х. Пилкингтон и У. Блюдиной, «сама модель культурного обмена между «центром» и «периферией» означает признание отношений господства и подчинения в обмене культурными сообщениями» [3, с. 21]. Речь здесь идет о подчинении одной культуры другой, когда «периферийная» культура не просто принимает, а вбирает в себя культуру «центра» и со временем перемещается на самый конец глобального тренда. В современном культурном пространстве роль такого «центра, как правило, выполняют США, Япония, государства Северной и Западной Европы, которые, как субъекты культурного обмена, начинают диктовать всему остальному миру свои культурные, нормы, правила, традиции. Роль «периферии» отведена, к примеру, и России, которая только недавно стала частью мирового сообщества, но которая имеет свою длительную историю культурного развития, в связи с чем не хочет мириться отведенным ей местом в глобальном культурном пространстве.

С другой стороны, ситуация в области культурных процессов складывается таким образом, что представители всевозможных культурных сообществ и групп, обнаружив друг друга благодаря развитию средств массовой коммуникации, создают виртуальные, транслокальные союзы, в которых каждый человек, будучи личностью, получает право на собственную самоидентификацию, что способствует к переходу в пространство «индивидуальных миров». Общение отдельных этнических групп в тех или иных сегментах культурного пространства является одним из проявлений социокультурной диверсификации, то есть «процесса проникновения этнокультурных общностей в общекультурную среду и формирование их единства» [4, с. 102].

А.И. Кравченнко определяет диверсификацию куль- туры как «распадение, расчленение единой культуры на составные части» [6, с. 144], когда глобальная культура «начинает разделяться на секторы, активность в которых ограничивается отдельными социокультурными общностями и в которых новыми методами происходит конструирование национальной, классовой или этнической идеи» [4, с. 103].

На наш взгляд, стремление народов к диверсификации и индивидуализации не означает конца эры массовой культуры и переходу к пространству «индивидуальных миров». Большая часть современных этнокультурных сообществ характеризуется лабильностью и непостоянством (как правило, это виртуальные сообщества или клубные культуры). Члены этих сообществ, именуемых «дискурсивными группами», тяготеют к своей собственной субкультуре, которой свойственен определенный набор своих собственных знаков, символов, ценностных ориентаций. Но не всегда подобные объединения носят долгосрочный характер. Со временем они трансформируются, переходя в новое состояние.

Члены каждой социальной группы или этнокультурного коллектива, как правило, тесно взаимосвязаны и зачастую однородны по своему составу. Их, прежде всего, объединяет сильное стремление - осознанное или неосознанное - к идентичности, которая и является основой диверсификации. При этом они не только тесно сплочены между собой, но и формируют четкую границу между «своим» сообществом и «чужаками», которые не должны вторгаться на их «территорию».

В то же время в пространстве культуры можно выделить сообщества, которым присуща слабая идентичность. Считая собственную культуру нестабильной, фрагментированной и не имеющей определенной ценности, а мировую культуру, наоборот, - многогранной и хорошо сконструированной, члены этих сообществ помогают раствориться собственной культуре в пространстве глобальной массовой культуры.

Итак, современная цивилизация диктует два условия существования культуры. С одной стороны, в последнее время этнокультурные сообщества и отдельные их представители в поисках национальной идентичности стали чаще обращаться к собственным корням, но при этом отвергая ценности и достижения иных культур (такие культуры носят название контркультур). С другой стороны, наблюдается взаимодействие субкультур, которые организуют единое поле глобальной культуры с риском рассеивания по этому полю «семян» отдельно взятой культуры, которые, прорастая, сольются с другими такими же «семенами», в связи с чем они могут напрочь лишиться своей неповторимости и самобытности («культурную диффузию» 
этносов увеличивают процессы миграции). Но именно это явление способствует возникновению феномена мультикультурализма, под которым понимается сосуществование многих субкультур в рамках той или иной региональной или национальной общности. Само же взаимодействие субкультур, их взаимовлияние и взаимопонимание определяется термином «интер-культурализм» $[9$, с. 310].

Любая субкультура представляет собой некую подсистему, ставшую частью иной, более крупной системы - мировой культуры [7, с. 64], но она образует и свое собственное, целостное, пространство, ибо имеет свой ценностный строй, обычаи, нормы, лексику, кодекс поведения. От контркультуры, стремящейся вытеснить доминирующую культуру, субкультуру отличает автономия, она не вступает в борьбу с доминирующей культурой чтобы заместить ее. Любая субкультура - это, прежде всего, особенности ментальности определенной социальной или этнической группы, настраивающие ее членов на отношения с «центром», в которому эта культура примыкает.

Но, говоря о сугубо идентичных ценностных доминантах той или иной субкультуры, не будем забывать, что сама культура, если рассматривать ее как глобальное явление, представляет собой своеобразную пирамиду, в которой по вертикали расположены ценности, признавать которые должных все без исключения члены мирового сообщества. В этом смысле культура едина и являет собой доминантную парадигму человечества. Деление культуры на национальные ее разновидности произошло примерно в XVIII-XIX вв. Последние же, в процессе формирования разных социальных классов и этнических групп, начали распадаться на локальные, этнографические, региональные культуры и трактоваться как субкультуры. Так появилась культура германских народов, афроамериканская культура, молодежная культура, рок- и поп-культуры и т.п.

Субкультура как феномен, расцветший в эпоху глобализации, а именно в XX веке, начала изучаться социологией, питающей интерес к идентичности различных групп населения, этнографией, делавшей предметом своих исследований быт и традиции коренных народов, далеких от универсальной, европейской, культуры, и непосредственно культурологией, изучающей многополярную и мультикультурную картину мира, народы которого открыты к взаимодействию и диалогу.

Сегодня культуры различных, больших и малых, народов объявлены ЮНЕСКО равноправными. И субкультуры теперь именуются таковыми не по отношению к национальной культуре, а по отношению к глобальной массовой культуре, с которой у них зачастую непростые и противоречивые отношения, поскольку послед- няя навязывает этим субкультурам определенные стереотипы, устоявшиеся в мировой культурной практике модели и принципы поведения. Но ведь и глобальная культура впитывает в себя элементы субкультур - даже в тех случаях, когда эти субкультуры стараются отмежеваться не только от нее, но и от друг друга.

Анализируя особенности современной культуры, следует отметить, что если в предшествующие периоды развития общества в нем доминировала европейская культура, то в последнее время границы этого культурного пространства значительно расширились. Не для кого не секрет, что в нынешнюю эпоху полным ходом идет экспансия восточной культуры, претендующей на лидерство. Материальная и духовная культура стран, исповедующих ислам, давно уже стала частью жизни современного общества.

Однако, исламская культура - не единственная культура, органично вписавшаяся в мультикультурное пространство глобальной цивилизации. В современном мире идет тенденция к универсализации культуры, отдельные «ячейки» которой способны вести диалог, отличаются плюрализмом и в то же время способны отстаивать свою национальную идентичность.

Мы живем в эпоху, когда понятие «граница» приобрело совершенно новый смысл. Сегодня даже границы между государствами становятся зыбкими, истончаются, открывая путь свободе передвижений. Границы между культурами еще в большей степени стираются, и мы уже не можем говорить о культуре-доминанте, диктующей свои правила, потому что мир многополярен и многонационален.

Процессы глобализации, стирающей грани между народами и диверсификации, генерирующей новые границы между различными сообществами и, соответственно, идентичностями, позволяет обнаружить многосоставность каждой этнической общности и определить общие и специфические черты разных национальных сообществ, входящих в глобальное культурное пространство.

Одной из основных черт современной культуры является тот факт, что в ней индивидуальное превалирует над коллективным, поскольку она развивалась в постмодернисткую эпоху, не признающую подчинения коллективистским моделям общественного сознания. И именно через глобализацию культурного пространства, состоящего из великого множества культур, влияющих друг на друга, проявляется единство человечества. Что касается диверсификации культурного пространства, то она способствует развитию толерантности, проявлению терпимости и организации межнационального общения в духе «диалога культур». 


\section{ЛИТЕРАТУРА}

1. Абрамова Н.В. Культура как фундаментальное понятие в современном обществе // Язык и межкультурная коммуникация: материалы Второй Международной науч.-практ. конф. Великий Новгород, $19-20$ мая 2011 г.: в 2 т. Т. 1. / Отв. ред. О.А. Александрова, Е.Ф. Жукова; НовГУ им. Ярослава Мудрого Великий Новгород, 2011. - С. 48 - 50.

2. Бабурин С.Н., Мунтян М.А., Урсул А.Д. Глобализация в перспективе устойчивого развития. - М.: Магистр : ИНФРА-М, 2011. - 496с.

3. Глядя на Запад: Культурная глобализация и российские молодежные культуры / Пер. с англ. 0. Оберемко и У. Блюдиной. - СПб: Алетейя, 2004. - 278 с.

4. Голубинская А.В. Диверсификация и унификация культур в глобальном веб-пространстве // Век глобализации. - 2017. - № 1. - C. 98-105.

5. Золотухин В.М. Культура, инновации и толерантность // Глобализация и пути сохранения традиционной культуры: сб. ст. Международной научно-практической конференции. - Кемерово: Кемеров. гос. ун-т культуры и искусств, 2009. - С. 79-85.

6. Кравченко А.И. Культурология: Словарь. - М.: Академический проект, 2000. - 671 с.

7. Малахова Е.В. Субкультура в культуре: мировоззренческий аспект // Социально-гуманитарное знание, 2015. № 8. - С. 63-65.

8. Стиглиц Дж.Ю. Глобализация: тревожные тенденции. - М.: Мысль, 2003. - 300 с.

9. Теоретическая культурология. - М.: Академический проект: Екатеринбург: Деловая книга; РИК, 2005. - 624 с.

10. Чумаков А.Н. Культурный код общественного развития: глобальные и локальные аспекты // Культура в условиях глобализации взгляд из России : монография / Под ред. А.Н. Чумакова. - М.: КНОРУС, 2017. - С. 8-32.

с С сметанкина Людмила Васильевна (Ismetankina.umo@mail.ru), Михалёв Сергей Александрович (sermichalev@yandex.ru).

Журнал «Современная наука: актуальные проблемы теории и практики»

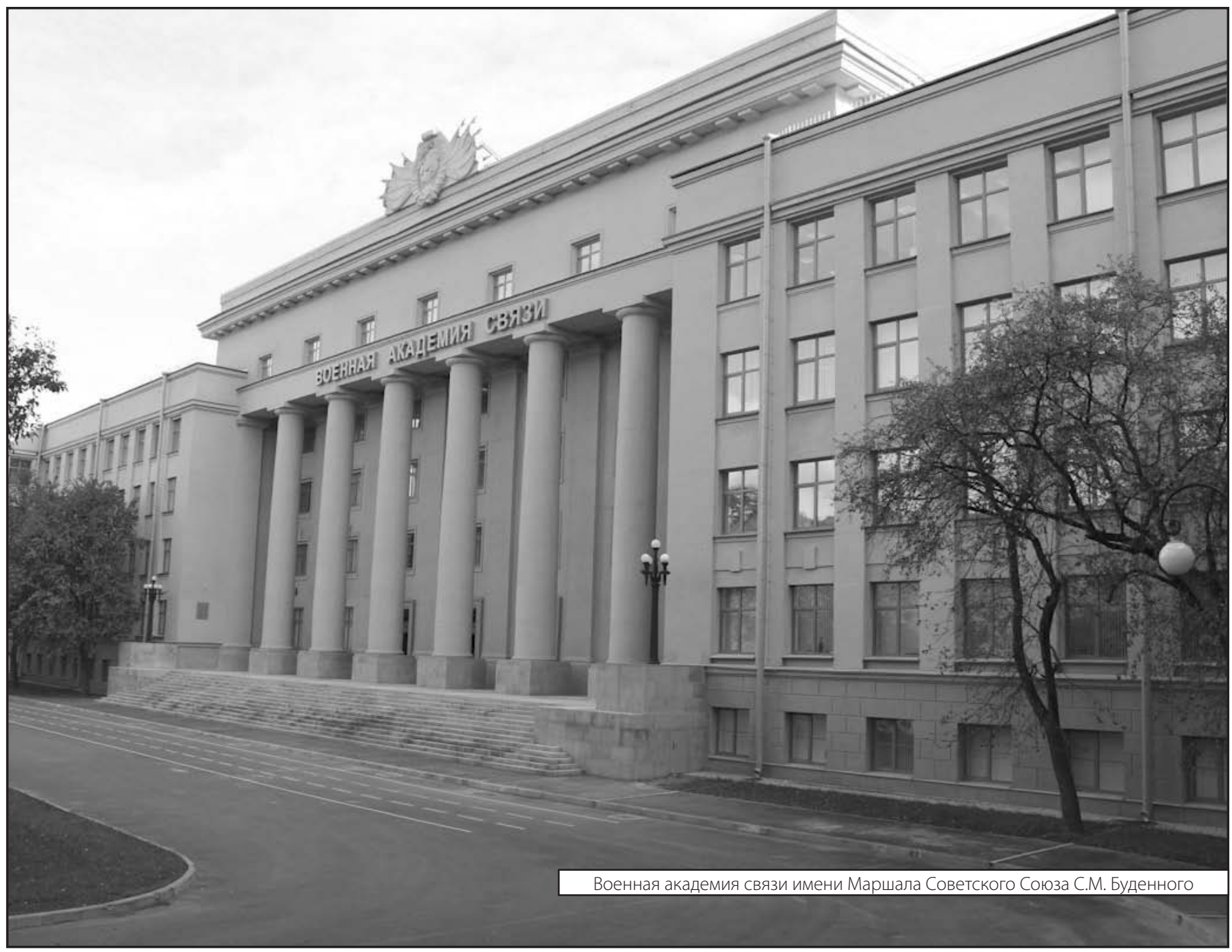

